\title{
Post-surgical Pyoderma Gangrenosum: A Retrospective Analysis of four Clinical Cases
}

Pyoderma gangrenosum is a rare neutrophilic, inflammatory disorder. A recent study from Finland has analysed patient records with postsurgical pyoderma gangrenosum with special focus on the diagnostic delay and treatment outcomes.

\section{ABSTRACT}

\section{Background}

Pyoderma gangrenosum (PG) is a rare neutrophilic disease that is characterised by the pathergy phenomenon, as it worsens with trauma. Post-surgical PG (PSPG) occurs in surgical incisions and is typically first misdiagnosed as a surgical site infection. The diagnostic delay in PSPG is often considerable.

\section{Hypothesis/Aim}

The aim of this study was to analyse patient records with PSPG that were diagnosed in our Department of Dermatology; with special focus on the diagnostic delay and treatment outcomes.

\section{Methods}

The records of four patient cases that were diagnosed with PSPG in our Department of Dermatology from 2017 to 2018 were analysed retrospectively.

\section{Results}

The average delay in diagnosis was 5 months, and the diagnosis could not rely on histological findings. Prednisolone treatment led to complete wound healing in three cases. In one case, switching from prednisolone to cyclosporine eventually healed the wound.

\section{Conclusions}

The diagnostic delay was considerable, and prednisolone and cyclosporine were considered as effective treatments.

\section{Implications for clinical practice}

This report emphasises the importance of early sus- picion and recognition in PSPG cases, and early referral to dermatologist.

\section{INTRODUCTION}

Pyoderma gangrenosum (PG) is a rare neutrophilic, inflammatory disorder. The typical presentation involves a papulo-pustule with violaceous inflamed borders evolving into enlarging, painful, undermined wounds. ${ }^{1}$ However, the clinical picture can vary greatly. Therefore, diagnosing these wounds can be challenging for the clinician. Recently, two reports on the diagnostic criteria have been published. ${ }^{2,3}$ It is important to keep in mind that PG is usually a diagnosis of exclusion. Often, a positive response to immunosuppressive treatment ultimately confirms the diagnosis. ${ }^{1,2}$

Several reports have also described post-surgical PG (PSPG). 4,5 PSPG has been reported to occur most frequently after breast surgery, followed by cardiothoracic, abdominal, and obstetric surgeries. ${ }^{4}$ With PSPG, the association of typical PG comorbidities, such as inflammatory bowel disease (IBD), rheumatoid arthritis, and haematologic malignancies, may not be strong. ${ }^{6}$ The real challenge in PSPG for both the clinician and patient is the delay in diagnosis. Typically, it is first misdiagnosed as a surgical site infection (SSI), but the wounds continue to enlarge or remain unhealed despite revisions and antibiotic treatment. ${ }^{4}$

\section{METHODS}

This retrospective study analysed four patient cases that were diagnosed with PSPG in our Department of Dermatology from 2017 to 2018

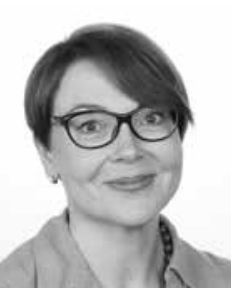

Kirsi Isoherranen $M D, P h D$, Specialist in Dermatology and Allergology. Helsinki University Central Hospital and Helsinki University, Wound Healing Centre and Dermatosurgery Unit, Finland
Correspondence: kirsi.isoherranen@hus.fi

Conflicts of Interest: None 
(Table 1). Data from patient records were collected and included comorbidities, type of surgery, diagnostic delay (assessed from first symptoms to the diagnosis date), histological report, treatment, and time to complete wound healing after starting immunosuppressive therapy. This retrospective study protocol followed the ethical guidelines of the Declaration of Helsinki (2013). Photographs were included after permission from the patients was obtained.

\section{RESULTS}

Patient characteristics are shown in Table 1. One patient had IBD (colitis ulcerosa), and one patient had rheumatoid arthritis (Figures 1a and 1b). Histology was not specific in most of the cases. The diagnosis was mainly established by the following criteria: the clinical picture and wound history, lack of response to earlier treatments (e.g., revisions, antibiotics), and a positive response to immunosuppressive therapy. The average time from the onset of symptoms until diagnosis was 5 months. Initially, treatment relied on prednisolone in all patients. In one patient, prednisolone was switched to cyclosporine, after which the wound eventually healed (Figures 2 a,b,c and d). Local wound therapy was designed according to the TIME ( $\mathrm{T}=$ tissue, $\mathrm{I}=$ infection/inflammation, $\mathrm{M}=$ moisture, $\mathrm{E}=\mathrm{edge}$ ) protocol. ${ }^{7}$

\section{DISCUSSION}

PG was first described by a French dermatologist named Brocq in $1916 .{ }^{8}$ It is an uncommon neutrophilic disorder, which presents as inflamed pustules and ulcers similar to an infectious disease. ${ }^{1}$ This clinical picture and negative histology in many cases render the diagnosis challenging. However, holistic patient assessment is essential and aids the diagnosis in these patients. "It is not the hole in the patient but the whole patient" ${ }^{\prime \prime}$ is a valid argument in PG patients. Different comorbidities, such as IBD, haematologic malignancies, and rheumatoid arthritis, can give

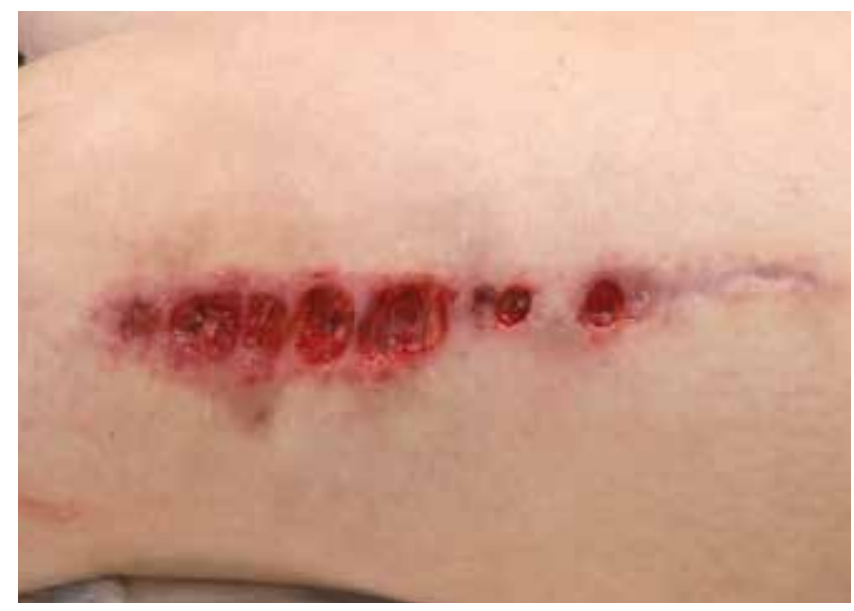

clues for PG diagnosis. ${ }^{9}$ Because IBD is such a common comorbidity, any wounds of interest in a patient with IBD can be considered a PG wound, until otherwise proven. Importantly, PG lesions occur in up to $50 \%$ of cases and are most commonly located at sites of cutaneous trauma, such as venepuncture, laparoscopy, and surgical incisions; this phenomenon is known as pathergy. PSPG refers to the development of PG at surgical sites in the immediate post-operative period, typically 1 week after surgery. ${ }^{5}$ The literature has described SSI as a frequent misdiagnosis, and mortality has been reported. ${ }^{4,5,11}$ However, the ulcers do not respond to antibiotic therapy and continue to enlarge after revisions, due to the pathergy phenomenon. ${ }^{4}$ From the patient's perspective, there is a substantial delay in diagnosis time and decreased health-related quality of life due to pain, continuous wound management, and unnecessary surgical treatments.

The aim of this study was to retrospectively analyse PSPG patients who were diagnosed and treated in our Dermatology Unit. The average delay in diagnosis was 5 months, which was the time from first symptoms to first dermatologic consultation. We believe this to be quite a long time, as PG ulcers usually heal very slowly after exact diagnosis and optimal treatment. The treatment relies on immunosuppressive therapy, and the first-line treatment option is high-dose prednisolone. After the suppression of inflammatory activity, a steroid-sparing agent is often combined to avoid the adverse reactions of high-dose steroids. ${ }^{12}$ However, in a randomised multicentre trial with 112 participants, cyclosporin and prednisolone did not differ across a range of objectives and patient-reported outcomes. Thus, it was concluded that the first-line drug should be decided based on each patient's characteristics. ${ }^{13}$ In hard-to-heal PG wounds, biologic treatment is also an option. ${ }^{14}$ When the inflammatory reaction has been reduced by immunosuppressive therapy, negative-pressure

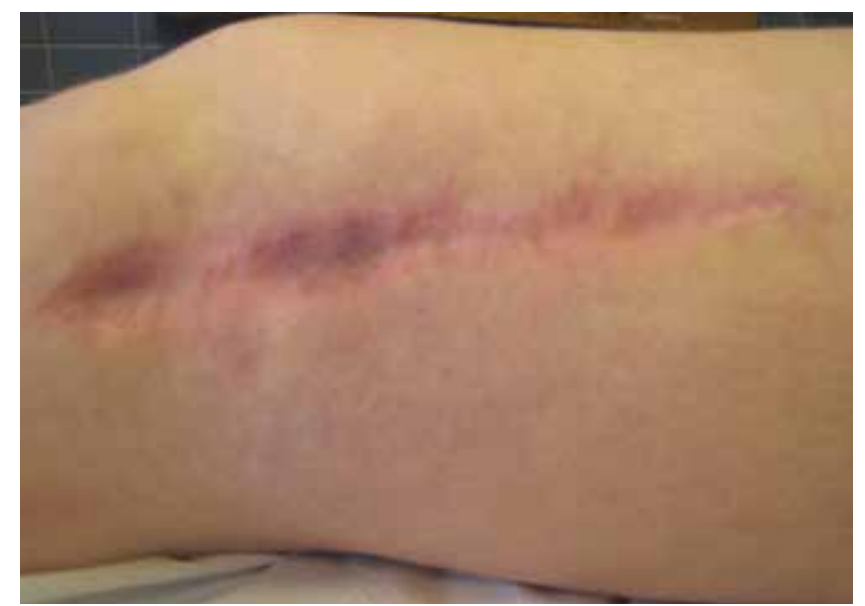

Figures $1 \mathrm{a}$ and $1 \mathrm{~b}$. Post-surgical pyoderma gangrenosum in a 16-year-old girl after knee arthroplasty. Figure 1a shows the wound before treatment. Figure $1 \mathrm{~b}$ shows complete wound healing after 2 months of prednisolone treatment. 
Table 1. Analysis of four post-surgical pyoderma gangrenosum patient cases.

\begin{tabular}{|c|c|c|c|c|c|}
\hline PATIENT & OPERATION & $\begin{array}{l}\text { DELAY IN } \\
\text { DIAGNOSIS }\end{array}$ & HISTOLOGY & TREATMENT & $\begin{array}{l}\text { TIME FOR } \\
\text { COMPLETE WOUND } \\
\text { HEALING }\end{array}$ \\
\hline Male 59 years & $\begin{array}{l}\text { Liberation of } \\
\text { the ulnar nerve } \\
\text { in the left arm }\end{array}$ & 5 months & $\begin{array}{l}\text { Granulation } \\
\text { tissue and mixed } \\
\text { inflammatory } \\
\text { cell infiltrate with } \\
\text { neutrophils }\end{array}$ & $\begin{array}{l}\text { 1. Prednisolone } \\
20 \mathrm{mg} / \text { day }+ \\
\text { mycophenolate } \\
\text { mofetil } 2000 \mathrm{mg} / \\
\text { day for } 9 \text { months } \\
\text { 2. Ciclosporine } \\
100 \mathrm{mg} \times 2\end{array}$ & $\begin{array}{l}\text { After starting } \\
\text { cyclosporine, } \\
5 \text { months }\end{array}$ \\
\hline $\begin{array}{l}\text { Female } 16 \text { years } \\
\text { Comorbidities: } \\
\text { Rheumatoid } \\
\text { arthritis }\end{array}$ & $\begin{array}{l}\text { Rotation } \\
\text { osteotomy } \\
\text { due to } \\
\text { femoral } \\
\text { fracture }\end{array}$ & 4 months & $\begin{array}{l}\text { Granulation } \\
\text { tissue with } \\
\text { a lymphocytic } \\
\text { infiltrate }\end{array}$ & $\begin{array}{l}\text { Prednisolone } \\
30 \mathrm{mg} / \text { day }\end{array}$ & 2 months \\
\hline Female 33 years & $\begin{array}{l}\text { Mastectomy } \\
\text { due to BRCA1- } \\
\text { mutation }\end{array}$ & 11 months & $\begin{array}{l}\text { Biopsy not } \\
\text { taken, clinical } \\
\text { diagnosis }\end{array}$ & $\begin{array}{l}\text { Prednisolone } \\
40 \mathrm{mg} / \text { day }\end{array}$ & 1 month \\
\hline $\begin{array}{l}\text { Female } 31 \text { years } \\
\text { Comorbidities: } \\
\text { Colitis ulcerosa }\end{array}$ & $\begin{array}{l}\text { Knee } \\
\text { arthroplasty }\end{array}$ & 1 month & $\begin{array}{l}\text { Neutrophilic } \\
\text { inflammation }\end{array}$ & $\begin{array}{l}\text { Prednisolone } \\
30 \mathrm{mg} / \text { day }\end{array}$ & 2 months \\
\hline
\end{tabular}

wound therapy and skin grafting are recommended options for reducing healing time. ${ }^{15}$

In our patients, prednisolone treatment led to complete wound healing in three cases during a period of 1-2 months. This prompt response to immunosuppressive therapy ultimately confirmed the diagnosis of PSPG. In one case, prednisolone $20 \mathrm{mg} /$ day for 9 months was ineffective, but cyclosporine eventually led to wound healing during a period of 5 months. The ineffectiveness of prednisolone in this case could potentially be influenced by the relatively low dose $(20 \mathrm{mg} /$ day $)$ that was used, as the patient weighed $101 \mathrm{~kg}$. Usually, the recommended dose of prednisolone ranges from $0.5-0.75 \mathrm{mg} / \mathrm{kg} /$ day. ${ }^{13}$ It is important to note that histology was not specific for PG in any of our cases. Typical histological findings were hypergranulation and mixed inflammatory infiltrate. Therefore, it is important that PG is not excluded by histological findings alone. In addition, the value of histology depends strongly on the site of biopsy. Optimally, surgeons and surgical nurses should be aware of this entity and recognise "danger" signs that highlight the need for dermatologic consultation. These signs include a previous history of PG, familial history of PG, IBD, haematologic malignancy, rheumatoid arthritis, negative wound swabs or unresponsiveness to antibiotic therapy, violaceous wound borders, and enlargement of wounds by revisions. ${ }^{4,5}$ Indeed, PG is a diagnosis that clinicians "wish you had never operated on". ${ }^{16}$

Finally, PG and PSPG are part of the family of atypical wounds, which deserve better recognition and treatment among health care professionals. The European Wound Management Association (EWMA) has established a working group to gather the best available knowledge on atypical wounds, and the EWMA Document on Atypical Wounds will be published in spring 2019. This document is targeted at increasing awareness of the clinical picture, diagnosis, and treatment of these wounds. It also aims to provide practical advice on some of the challenges that typically arise in the diagnosis or treatment of inflammatory and vasculopathy wounds, such as PG, malignant wounds, and cutaneous vasculitis. ${ }^{17}$

\section{CONCLUSIONS}

PSPG is an important differential diagnosis for SSI. Prompt suspicion and recognition, as well as a dermatologic consultation, are necessary for favourable outcomes in these cases. The disease can also be fatal. Despite a considerable delay in diagnosis, our study showed favourable outcomes after exact diagnosis and immunosuppressive treatment. 

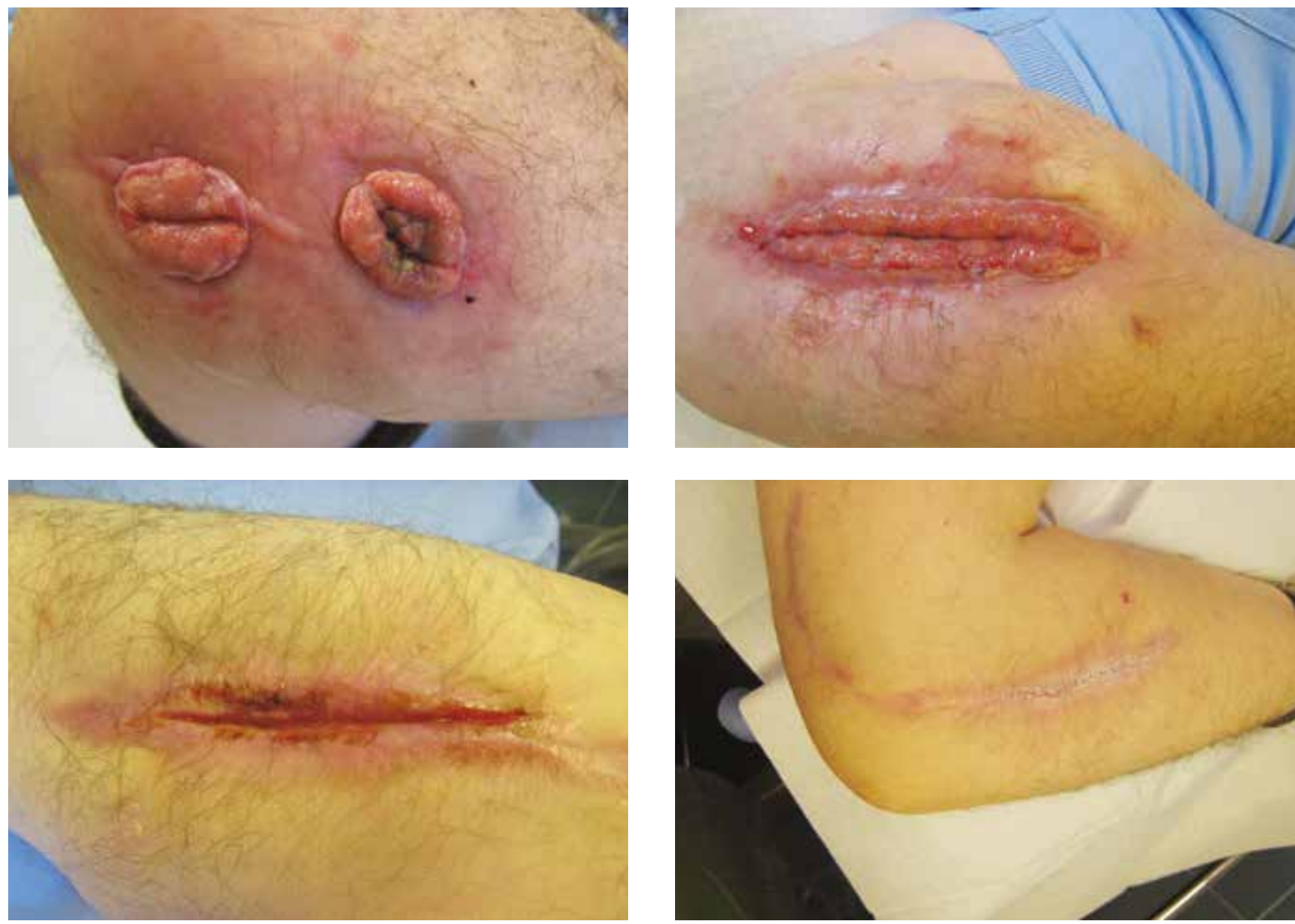

Figures $2 a, b, c$ and $d$. Post-surgical pyoderma gangrenosum in the surgical scar of an ulnar nerve liberation. Figure $2 a$ shows the wound before treatment. Figure $2 \mathrm{~b}$ shows 9 months after prednisolone treatment. Figure $2 \mathrm{c}$ shows 1 month after the starting of cyclosporine. Figure $2 \mathrm{~d}$ shows complete wound healing after 5 months of cyclosporine treatment.

\section{REFERENCES}

1. Hadi A and Lebwohl M. Clinical features of pyoderma gangrenosum and current diagnostic trends. J Am Acad Dermatol 2011; 64:950-954.

2. Jockenhöfer F, Wollina U, Salva KA, Benson S, Dissemond J. The PARACELSUS score: a novel diagnostic tool for pyoderma gangrenosum. $\mathrm{Br} \mathrm{J}$ Dermatol 2018; doi:10.1111/bjd.1640

3. Maverakis E, Ma C, Shinkai K, Florentino D, Callen JP, Wollina U et al. Diagnostic criteria of ulcerative pyoderma gangrenosum: A Delphi Consensus of International Experts. JAMA Dermatol 2018; 154 461-466.

4. Zuo KJ, Fung E, Tredget EE, Lin AN. A systematic review of post-surgical pyoderma gangrenosum: identification of risk factors and proposed management strategy. J Plast Reconstr Aestehtic Surg 2015;68 (3):295.303.

5. Larcher L, Schwaiger K, Eisendle K, Ensat F, Heinrich $\mathrm{K}$, di Summa P et al. Aesthetic breast augmentation mastopexy followed by post-surgical pyoderma gangrenosum (PSPG): Clinic, treatment, and review of the literature. Aesthetic Plast Surg 2015; 39:506513.

6. Tolkachjov SN, Fahy AS, Cerci FB, Wetter DA, Cha SS, Camilleri MJ. Postoperative pyoderma gangrenosum: a clinical review of published cases. Mayo Clin Proc 2016;91(9): 1267-79.
7. Schultz GS, Sibbald RG, Falanga V, Ayello EA Dowsett $\mathrm{C}$, Harding $\mathrm{K}$ et al. Wound bed preparation: a systematic approach to wound management. Wound Rep Reg 2003;11:1:1-28.

8. Farhi $D$. The clinical and histopathological description of geometric phagedenism (Pyoderma Gangrenosum) by Louis Brocq one century ago. JAMA Dermatol 2008; 144(6): 755.

9. International Consensus (2012) Optimising Wellbeing in People Living with a Wound. Available at: www. woundsinternational. com/media/issues/554/files/ content 10309.pdf

10. Su WP, Davis MD, Weening RH, Powell FC, Perry $\mathrm{HO}$. Pyoderma gangrenosum; clinicopathologic correlation and proposed diagnostic criteria. Int J Dermatol 2004;43:790-800.

11. Tanini S, Calugi G, Lo Russo G. Combination of negative pressure wound therapy and systemic steroid therapy in postsurgical pyoderma gangrenosum after reduction mammoplasty; a case of proven efficacy and safety. Dermatology Reports 2017; (9):7209.

12. Herberger $\mathrm{K}$ et al. Treatment of pyoderma gangrenosum: retrospective multicenter analysisof 121 patients. Br J Dermatol 2016; 175 :1070-1072.
13. Ormerod AD, Thomas KS, Graig FE, Mitchell E, Greenlaw N, Norrie J et al. Comparison of the two most commonly used treatments for pyoderma gangrenosum: results of the STOP GAP randomized controlled trial. BMJ 2015;Jun12;350:h2958.

14. Brooklyn TN, Dunnill MG, Shetty A, Bowden JJ, Williams JD, Griffiths $C E$, et al. Infliximab for the treatment of pyoderma gangrenosum: a randomized, double blind, placebo controlled trial. Gut 2006; 55(4):505-509.

15. Pichler M, Thuile T, Gatscher B, Tappeiner L, Deluca $J$, Larcher $L$ et al. Systematic review of surgical treatment of pyoderma gangrenosum with negative pressure wound therapy or skin grafting. JEADV 2017;31(2): e61-e67.

16. Hradil E, Jeppsson C, Hamnerius N, Svensson Å. The diagnosis you wish you had never operated on: pyoderma gangrenosum misdiagnosed as necrotizing fascitis- a case report. Acta Orthopaedica 2017; 88:231-233.

17. EWMA Document. Atypical wounds: Best Clinical Practice and Challenges. Document submitted for publication. 